\title{
Incorporación directa e indirecta de los préstamos de origen ruso al español y nuevos términos*
}

SVETLANA MOLKOVA

Universidade da Coruña

svetlana.molkova@udc.es

\section{INTRODUCCIÓN}

El préstamo lingüístico es uno de los mecanismos neológicos más enriquecedores de un idioma. Sea para cubrir una laguna léxica, sea por el prestigio de una lengua ante otra, el préstamo de un elemento perteneciente a otro idioma aporta nuevo material al sistema lingüístico.

Los préstamos son consecuencias de contactos - directos o indirectos- de las culturas. Las huellas léxicas que una nación deja en el vocabulario y la estructura lingüística de otra están determinadas, a su vez, por la naturaleza de las relaciones que dichas culturas han desarrollado a lo largo de su camino histórico. Mientras una estrecha convivencia propicia un intercambio intenso de elementos lingüísticos, el distanciamiento geográfico condiciona un alto grado de ignorancia acerca de la cultura $-\mathrm{y}$ la lengua, como una parte de la cultura - ajena.

Rusia y España son dos peregrinos cuyos caminos se han cruzado en pocas ocasiones. Sin embargo, aunque poco duraderos, los contactos entre estos dos países han ido dejando constancia del saber mutuo en los respectivos idiomas. En este trabajo estudiaré los elementos de origen ruso registrados en una selección de fuentes lexicográficas de la lengua española, centrándome en la vía - directa o indirecta - de su entrada en español, y reflexionaré acerca de la necesidad de la incorporación de un número más elevado de dichos elementos en los diccionarios españoles.

La investigación, por lo tanto, constará de dos etapas. En primer lugar, se realizará una comparación de los datos etimológicos en las entradas de los términos de origen ruso registrados en la vigésima tercera edición del Diccionario de la lengua española con la información proporcionada por una serie de fuentes lexicográficas previamente seleccionadas, con el objetivo de definir las vías — directa o indirecta - de la incorpo-

* La presente investigación ha sido financiada por el Ministerio de Educación, Cultura y Deporte dentro del marco de las ayudas del Programa de Formación del Profesorado Universitario 2013 (FPU 2013, referencia: 13/02067), dentro de las actividades del Grupo Hispania de la UDC (G000208). Los resultados del estudio fueron expuestos, de forma resumida, en el III Congreso Internacional de Neología en las Lenguas Románicas (Salamanca, 22-24 de octubre de 2015). 
ración de dichos préstamos en el idioma español. En segundo lugar, se investigará la necesidad de la incorporación en el $D R A E$ de un número más elevado de términos rusos que presentan registro esporádico en otros diccionarios o bases de datos de neologismos.

Dicha investigación presenta un intento de solucionar — hasta donde sea posibleel problema de la escasez de datos acerca de los préstamos de origen ruso en español y podría ser de utilidad en los estudios acerca del léxico español y, entre otras posibilidades, en las clases del español como lengua extranjera. Para conseguir una comprensión más profunda acerca de la incorporación de los términos de origen ruso en el vocabulario del español, parece oportuno empezar por un breve recorrido histórico de las relaciones entre España y Rusia.

\section{BREVE HISTORIA DE LAS RELACIONES ENTRE ESPAÑA Y RUSIA}

Los primeros contactos diplomáticos entre España y Rusia datan del siglo XVI; a pesar de ello, hasta el último cuarto del siglo XX, las relaciones entre estos dos países se caracterizaron por la alternancia de períodos de acercamiento y de distanciamiento político e ideológico. De acuerdo con los datos que presentan Manuel de la Cámara (2010) y Magdalena Garrido Caballero (2008), en el siglo XVI, el Gran Príncipe de Moscú Basilio III y el emperador de Sacro Imperio Carlos V confirman sus intenciones de mantener buenas relaciones entre los dos pueblos enviando las correspondientes misiones diplomáticas. El zar Iván el Terrible reafirma el interés por la colaboración con una nueva misión. No obstante, no es antes del 1722 cuando, tras la recepción del embajador de Rusia, el príncipe Serguei Golítsin, por Felipe V y la visita del Duque de Liria a Pedro I el Grande, se produce el establecimiento de relaciones diplomáticas plenas.

Sin embargo, la ascensión al trono de Ana Ioánnovna de Rusia, tan solo 37 años más tarde, provoca la ruptura de las relaciones por parte de España, que no reconoce los derechos a reinar de la monarca. La necesidad de una alianza contra la fuerza francesa lleva al país a intentar, a finales del siglo XVIII, firmar nuevos acuerdos con Rusia, pero la Orden de Malta origina un conflicto entre los dos imperios, que se declaran la guerra en 1799. La agresión francesa vuelve a unir los países cuando Alejandro I ocupa el trono, si bien ya en 1822 Rusia, como parte de la Santa Alianza con Prusia y Francia, manda un numeroso ejército a España con el fin de restablecer el absolutismo y más tarde, entre 1833 y 1856, cierra su embajada por no reconocer los derechos de Isabel II al trono. Tras la Guerra de Crimea de 1853-1855, se restablecen las relaciones entre los dos países y se mantienen hasta la Revolución de Octubre de 1917, que provoca la retirada de los respectivos embajadores. En 1933 Stalin nombra embajador de Rusia en España a uno de los padres de la revolución rusa, Anatoli Lunacharski, que fallece antes de ejercer el cargo. En 1936 Rusia y España de nuevo intercambian sus embajadores y se abre un consulado soviético en Barcelona.

La victoria de Franco en 1939 da inicio a una nueva etapa de distanciamiento, de casi cuarenta años de duración, a lo largo de la cual los contactos entre los dos países son prácticamente inexistentes (aparte del encuentro militar entre las tropas de la Unión Soviética y la División Azul entre 1941 y 1943). A finales de los años sesenta destaca el rápido crecimiento de las relaciones comerciales entre la URSS y España, que abren 
las representaciones comerciales en las respectivas capitales, encargándoles también las relaciones consulares. Los países intensifican más aún los contactos después de la muerte del general Franco, restableciendo las relaciones diplomáticas en 1977. España reconoce oficialmente la Federación Rusa en 1991 tras la disolución de la Unión Soviética. Como reconocimiento de la importancia de la colaboración entre los países, los aniversarios del restablecimiento de las relaciones diplomáticas se celebran tanto en España como en Rusia con numerosos actos, exposiciones y conferencias.

En los últimos años, gracias principalmente a la intensificación de los contactos políticos, las relaciones hispano-rusas se han elevado a un nivel cualitativamente nuevo. Como confirmación de la creciente colaboración se renueva cada cinco años el Tratado de Amistad y Cooperación, firmado en 1994, que recoge las bases jurídicas de la relación política entre España y Rusia, y los dirigentes de ambos países realizan visitas mutuas, cada vez más frecuentes, para definir nuevas vías de cooperación.

Los intercambios comerciales entre Rusia y España aumentan su volumen. La infraestructura, el transporte, la agroalimentación, el automovilismo, la moda, la construcción, el turismo, el sector energético y muchos otros ámbitos presentan un gran potencial - según los datos del comercio, todavía no lo suficientemente desarrolladode colaboración entre dos países (Yákovlev 2011). Las relaciones culturales, educativas y científicas también han recibido un impulso considerable. En la difusión de la lengua y cultura española destaca la labor de la sede del Instituto de Cervantes inaugurada en Moscú en el año 2002. Especialmente importante para el desarrollo de la colaboración en los ámbitos de la educación, la investigación y la ciencia fue también el II Encuentro de Rectores de Universidades Españolas, Rusas e Iberoamericanas celebrado en 2011 en Moscú (la primera sesión tuvo lugar en 2009 en Madrid); en el Encuentro se trataron las posibilidades de colaboración, altamente beneficiosa tanto para Rusia como para España, en el ámbito científico-técnico.

Como se aprecia en este recorrido histórico, hasta el último cuarto del siglo XX los contactos hispano-rusos carecían de estabilidad; largos períodos de alejamiento se alternaban con etapas esporádicas de colaboración. La falta de contactos permanentes impidió el intercambio ideológico constante causando un alto grado de desconocimiento cultural mutuo. Sin embargo, aunque poco duraderos, los contactos entre dos países iban dejando en el idioma constancia del saber acerca de las costumbres y realidades culturales, estructura política y acontecimientos históricos de la vida del otro pueblo. El establecimiento de una correspondencia más estable entre España y Rusia en el siglo $\mathrm{XX}$ determinó una mayor aproximación entre dos culturas $\mathrm{y}$, como consecuencia, una mayor necesidad de denominar las realidades y los conceptos pertenecientes a la cultura e historia del otro pueblo.

El creciente conocimiento histórico-cultural condicionó, por lo tanto, el uso más frecuente de los préstamos lingüísticos. Los conceptos culturales más llamativos del pueblo español, los objetos cotidianos que forman parte de su patrimonio, igual que las nociones y los eventos relevantes de la historia y política del país, han encontrado su reflejo en el vocabulario de la lengua rusa, de la misma manera que el idioma español dispone de préstamos de origen ruso - elementos en los que se centrará este estudio- 
para denominar las realidades correspondientes a la nación rusa. A continuación, procederé con el análisis de los préstamos de origen ruso registrados en el DLE-2014.

\section{ANÁLISIS ETIMOLÓGICO DE LOS PRÉSTAMOS DE ORIGEN RUSO EN ESPAÑOL}

De acuerdo con los datos de mi investigación, los contactos histórico-culturales entre España y Rusia se hallan reflejados hoy en día en no menos de treinta y ocho palabras de origen ruso registradas en las páginas de la vigésima tercera edición del Diccionario de la lengua española de la Real Academia Española. El estudio de dichos términos permite afirmar que los préstamos de origen ruso en español forman, según su significado, su uso y su integración en el idioma, dos grupos.

El primer grupo consta de los «exotismos» (Haensch 1975, en Gómez Capuz 1998: 38) que designan objetos y conceptos de la vida cotidiana y la cultura de Rusia - como son los casos de balalaika y rublo ${ }^{1}$ - y denominan ideas y eventos relacionados con la historia y política del país — por ejemplo, sóviet (también soviet) y ucase-. Dichas unidades se caracterizan por un bajo grado de integración en el idioma y, generalmente, poco uso en los textos de los corpus, debido a que reflejan realidades ajenas a la cultura española.

El segundo grupo contiene los rusismos y los términos de origen ruso que designan las realidades y los acontecimientos histórico-políticos de Rusia (y de la Unión Soviética), algunos de los cuales han afianzado su uso en español conservando el significado original de la lengua modelo (la mayoría de dichos términos - como bolchevique y kremlin - se hallan en proceso de asimilación al sistema léxico del español), mientras que otros han ampliado los significados originales y han recibido uso como términos genéricos, propios de la lengua (dichos términos, tales como checa y pogromo, están totalmente integrados en el léxico del español). Estos elementos, en su mayoría, presentan un uso frecuente en la prensa política, de economía y finanzas, en las novelas, los relatos y los textos de ciencias sociales y se caracterizan por un alto nivel de asimilación fónica, gráfica y morfológica. Por lo tanto, entre los rusismos y los términos de origen ruso en español se hallan tanto los exotismos como los elementos completamente integrados en el idioma.

Sin embargo, a pesar de deber su origen a la lengua rusa y reflejar, por lo tanto, realidades y conceptos propios de la cultura e historia de Rusia o de la Unión Soviética, algunos de estos vocablos no han sido incorporados en el vocabulario del español directamente del ruso y no pueden, por lo tanto, considerarse rusismos. Dado que el registro etimológico de los préstamos requiere un estudio de gran complejidad, la comparación de dichos datos en varios diccionarios podría servir de punto de partida para profundizar en la historia de la incorporación de los préstamos con el objetivo de reafirmar su procedencia o corregir una indicación etimológica errónea. Otro asunto que requiere consideración es la necesidad de la incorporación en el $D R A E$ de un número más elevado de términos rusos, muchos de los cuales presentan registros esporádicos en otros diccionarios. De ahí que esta investigación, como se ha indicado antes, se

\footnotetext{
${ }^{1}$ El uso de la cursiva con los términos de origen ruso tiene una función metalingüística y no corresponde a la escritura habitual de dichos términos.
} 
divida en dos etapas: en primer lugar, analizaré las vías — directa o indirecta — de la entrada de las unidades de origen ruso registradas en la vigésima tercera edición del $D R A E$ y, en segundo lugar, reflexionaré acerca de la necesidad de la incorporación de un mayor número de dichos elementos en los diccionarios españoles.

\subsection{Incorporación directa e indirecta de los préstamos del ruso al español}

Con el objetivo de distinguir los verdaderos rusismos (términos del ruso que entraron en español vía lengua rusa) de los elementos de origen ruso incorporados al español mediante un «étimo inmediato» (Pratt 1980), entre los treinta y ocho términos de origen ruso que aparecen en las páginas del $D L E-2014^{2}$ he contrastado los datos etimológicos de las siguientes fuentes lexicográficas: las veintitrés ediciones del $D R A E$, el Nuevo diccionario histórico del español (consulta en mayo de 2016; a partir de aquí, NDHE), el Diccionario crítico etimológico castellano e hispánico de Joan Coromines y José Antonio Pascual (a partir de aquí, DECH), el Diccionario del español actual de Manuel Seco, Olimpia Andrés y Gabino Ramos (DEA), Bolchevik, mazout, toundra et les autres: dictionnaire des emprunts au russe dans les langues romanes de Éva Buchi, el Diccionario esencial de la lengua española, el Diccionario del estudiante, el Diccionario de uso del español de María Moliner (DUE), el Diccionario general de la lengua española Vox (a partir de aquí, el Diccionario Vox) y Larousse: Gran Diccionario de la Lengua Española (el Diccionario Larousse) —obras del prestigio reconocido que registran en sus páginas los vocablos del uso verificado en el español actual y proporcionan datos sobre su origen-.

De acuerdo con la vigésima tercera edición del DRAE, de los treinta y ocho préstamos de origen ruso que he localizado en sus páginas, treinta y dos pueden considerarse rusismos, dado que, según los datos del DRAE, se incorporaron al español directamente del ruso. Son los casos de astracán, balalaica, beluga, blinis, checa, combinado (en su segunda acepción), constructivismo, cosmonauta, dacha, duma, gulag, inteligencia (en su segunda acepción), isba, katiuska, kopek (también copec), kremlin, nomenklatura, perestroika, pogromo, politburó, pope, rublo, samovar, sóviet (también soviet), tokamak, troika (también troica), ucase, uniata, versta, vodka, zar y zarévich. Los restantes seis elementos provienen del ruso o fueron transferidos al español a través del ruso como uno de los idiomas intermediarios, pero entraron en el idioma como resultado del contacto directo con otra fuente lingüística. Se trata de los elementos bolchevique, cebellina, estepa, hospodar, icono (también ícono) y menchevique.

Sin embargo, algunas de las fuentes etimológicas que he revisado presentan datos que difieren de las informaciones etimológicas del DLE-2014. Las diferencias anotadas justifican la necesidad de una investigación más detallada acerca de la incorporación de ciertos términos de origen ruso al español. Un estudio más profundo puede llevar a reafirmar la vía de entrada de estos préstamos en español o modificar la indicación de su procedencia.

${ }^{2}$ Dado que a lo largo del análisis se utilizan ediciones distintas del $D R A E$, para indicar la edición a la que se hace referencia se introducirá el año de su publicación, como en el caso de DLE-2014. Las ediciones previas a la vigésima segunda han sido consultadas en el Nuevo tesoro lexicográfico. 
A continuación, procederé a citar los términos de origen ruso registrados en el $D L E$ 2014, indicando los datos etimológicos correspondientes que presentan las fuentes arriba mencionadas y centrándome, sobre todo, en detallar las diferencias anotadas en relación con la marca de procedencia. Agruparé los términos en dos apartados: por un lado, los rusismos y las palabras de origen ruso cuya etimología no presenta disimilitudes en las obras consultadas; y, por otro lado, los lexemas de origen ruso con distintas marcas de procedencia en los diccionarios revisados.

\subsubsection{Coincidencia de los datos etimológicos en las fuentes lexicográficas}

En primer lugar, trataré los términos de origen ruso cuya procedencia se describe de forma semejante en las fuentes lexicográficas seleccionadas. Dichas unidades pueden, a su vez, ser divididas en dos grupos: términos considerados como rusismos y elementos de origen ruso que presentan otro étimo inmediato en español. Seguiré con la descripción de dichos términos en este mismo orden.

Es relevante anotar que considero un término como rusismo en el caso de que esté indicado como procedente directamente del ruso en al menos una de las obras consultadas, puesto que no todos los diccionarios registran las palabras en cuestión y, en muchas ocasiones, dichos términos no van acompañados de ningún tipo de marca etimológica. Para ahorrar espacio, recogeré aquí dichos rusismos en la forma gráfica y con la mención etimológica que presenta la vigésima tercera edición del $D R A E$. De la misma manera, considero posible omitir los datos acerca de las fuentes que incluyen dichos términos con la indicación de su incorporación directa del ruso, dado que su mención complicaría la descripción sin aportar datos relevantes.

Por lo tanto, los términos que han recibido la consideración de rusismos tanto en el $D L E-2014$ como en los diccionarios consultados (al menos, en uno de ellos) son los siguientes:

blinis $^{3}$ (Del ruso bliny, pl. de blin ${ }^{4}$ ), checa (Acrón. del ruso Chrezvychainaya Komissiya 'Comisión Extraordinaria', nombre de la policía secreta desde 1917 hasta 1922), combinado —en su segunda acepción - (Del ruso kombinat), constructivismo (Del ruso konstruktivizm), cosmonauta (Del ruso kosmonavt, de kosmo- 'cosmo-' y -navt '-nauta'), dacha (Del ruso dacha; propiamente 'donación'), duma (Del ruso duma, de or. germánico), gulag (Del ruso gulag, acrón. de Glavnoe upravlenie ispravitel'no-trudovykh lagerei 'central administrativa de los campos de trabajo correccionales'), inteligencia — en su segunda acepción - (Del ruso intelligentzia), $k a-$ tiuska (Del n. p. ruso Katjuša, hipocorístico de Katja, y este de Ekaterina 'Catalina'), nomenklatura - también nomenclatura - (Del ruso nomenklatura, y este del lat. nomenclatūra 'lista de nombres'), perestroika (Del ruso perestroika 'reconstrucción'), pogromo (Del ruso pogrom 'devastación, destrucción'), rublo (Del ruso rubl,

${ }^{3}$ Buchi indica que el préstamo fue transmitido a las lenguas iberorrománicas a través del francés en el siglo XX; su descripción de dicho término en español no confirma, sin embargo, su teoría.

${ }^{4}$ En esta enumeración, se citan los datos etimológicos del $D L E-2014$. Para no dificultar la lectura del texto, se omiten de aquí en adelante las referencias tanto al DLE-2014 como a otros diccionarios cuando se incluyen los datos etimológicos que estos presentan. En el caso de que se cite otra edición del $D R A E$, se especificará en el texto. 
der. de rubitj 'cortar', por ser el antiguo rublo un pedazo cortado de una barra de plata), samovar ${ }^{5}$ (Del ruso samovar), sóviet — también soviet, Méx. y Ven.- (Del ruso sovét), tokamak (Acrón. del ruso toroidal kamera aksial), troika — también troica - (Del ruso trolka, der. de troe 'trío's'), uniata (Del ruso uniyata 'unido'), versta (Del ruso versta), vodka — también vodca- (Del ruso vodka, dim. de voda 'agua').

Cabe mencionar que las indicaciones etimológicas de muchos de los términos señalados sufrieron modificaciones en las ediciones anteriores del $D R A E$. Así, por ejemplo, toda una serie de estos rusismos se incluía en distintas ediciones del Diccionario sin ningún tipo de marca etimológica. Son los casos de duma, isba, rublo, samovar, pope y zar, entre otros.

Aparte de los rusismos, el DLE-2014 y los diccionarios consultados coinciden en la indicación etimológica de un número reducido de términos que proceden del ruso o se transmitieron al español mediante el ruso como lengua intermediaria, pero se incorporaron a la lengua mediante el contacto directo con otro idioma. Es importante destacar que en la descripción no menciono el registro de los términos en los diccionarios distintos del $D R A E$ en el caso de que no vayan acompañados de una marca etimológica. Las palabras descritas son las siguientes:

bolchevique: Según el DLE-2014, a pesar de proceder del ruso, dicho término se considera un galicismo, ya que se incorporó al español vía el francés: «Del fr. bolchevique, y este del ruso bolshevik; literalmente 'uno de la mayoría'». Sin embargo, el $D R A E-1936$ - la primera edición en incluir el vocablo - no ofrecía ninguna indicación etimológica del término, hecho que cambió en el $D R A E-1956$, que presentaba el adjetivo como un rusismo («Del ruso bolchevik, partidario del máximo»). La mención de su entrada en el vocabulario del español a través del francés se hace por primera vez en el $D R A E$-1992. Buchi también indica la incorporación de dicho lexema mediante el francés, sugerida, según explica la autora, por la morfología de la forma mayoritariamente utilizada (en -ique). Se anota, sin embargo, otra forma de carácter efímero del propio ruso - bolchevik y sus variantes bolchevick, bolchevich, bolshevik-, que le precedieron al galicismo. También se menciona el uso del término como sustantivo en las primeras etapas de su incorporación al español. El Diccionario Vox marca igualmente el término como galicismo («Préstamo del francés bolchevique y éste [sic] del ruso bolchevik...»), mientras que el Diccionario Larousse lo considera un rusismo («Del ruso mayoritario»).

cebellina. La indicación «Del fr. zibeline o del it. ant. zibellino, y estos del ruso sobolj 'marta'" " a partir del DRAE-1992 (con cambios en el orden en la marca etimológica de 1992) modificó la mención «Del ruso sobolj, marta» del DRAE-1956 que, a su vez, sustituyó «Del b. lat. zebellina [pellis, piel] de marta, y éste [sic] del ruso sobolj» del Diccionario de 1914, precedida por «Del b. lat. Sabellum, piel de marta; del eslabón zable» de la edición de 1884 , la primera marca etimológica que acompañó el término desde el Diccionario de autoridades. Destaca el cambio morfológico del término, que fue registrado como sustantivo en el Diccionario de autoridades, se

${ }^{5}$ Buchi señala que se trata de un préstamo de origen ruso incorporado vía el francés; su descripción, no obstante, parece insuficientemente documentada. 
utilizaba como sustantivo y adjetivo según las ediciones de 1803, 1817 y 1822 del $D R A E$, y apareció como adjetivo desde el DRAE-1832 (aunque desde 1832 hasta 1869 conservaba la indicación sobre su aplicación a la piel del animal llamado cebe1lina). El $D R A E$, por lo tanto, considera que el término podría ser un galicismo o un italianismo, dato apoyado igualmente por el DUE («del fr. zibeline o del it. ant. zibellino, del ruso sobolj, marta»).

El término presenta, además, la forma cibelina, igualmente recogida en los diccionarios. En su primera aparición en las páginas del DRAE, en 1936, el préstamo no posee marca etimológica; en 1956 se registra con la indicación «Del fr zibeline, y éste [sic] del ruso soboji, marta» que desaparece de nuevo en el $D R A E-1992$, lo que sugiere la incorporación completa del término al vocabulario español. El $D E C H$ de Coromines y Pascual sigue, sin embargo, reflejando la incorporación del término vía el francés («del fr. zibeline, fr. ant. sebelin, que vino de una lengua asiática por conducto del ruso sóbolĩ y el alem. zobel íd.»). Los autores añaden, sin embargo, que «La historia del vocablo no está bien averiguada. La trasmisión se hizo parcialmente por vía mediterránea y por conducto del italiano, según indican los testimonios de Huerta y del Viaje a Turquía (DHist.), pero las formas del S. XIII proceden del francés o del oc. cembelin, donde el vocablo se cruzó con cembel 'señuelo'. El alem. zobel ya se documenta en el S. XI. Kluge, Gamillscheg, s. v. Otra variante fr. es sable, de donde por comparación nuestro heráldico sable [Acad. ya 1817]» (Coromines y Pascual 2012 [1980-1991], s. v. cibelina). El DUE y el Diccionario Larousse también señalan que el adjetivo es un galicismo (DUE: «del fr. zibeline, del ruso sobolj», Larousse: «Del fr. lt fr. ant.»).

estepa. Designando un erial llano y extenso, el término se registra en el Diccionario de la lengua española en el año 1884 sin ninguna mención etimológica. Ya en la siguiente edición, el $D R A E-1899$, aparece como un rusismo («Del ruso steppe»). Al cabo de poco menos de cien años, en el $D R A E-1992$, la marca etimológica que acompaña el término lo define como un galicismo («Del fr. steppe»). Manteniendo la incorporación mediante el francés, el $D L E-2014$ señala el origen ruso del término («Del fr. steppe, y este del ruso step»). El Diccionario Larousse presenta el término como rusismo ( «Del ruso»), mientras que Buchi y el DECH coinciden con el DRAE en la consideración del préstamo como galicismo ( $D E C H$ : «tomado del ruso step f., íd., por conducto del fr. steppe»; Buchi: afirma - aunque sin documentación suficiente - que el término fue transmitido a las lenguas iberorrománicas a través del francés, que, a su vez, lo había incorporado del inglés).

hospodar. Desde el DRAE-2001, dicho préstamo es tratado como un préstamo del rumano («Del rumano hospodár, este del ucraniano hospodar, y este del ruso gospodar', de gospod', señor»). Su historia en el DRAE, sin embargo, es rica en cambios en la marca etimológica: el término se introduce en el $D R A E-1843$ sin indicación de procedencia, en el 1899 añade la marca «del ruso gospodarj, del gr. [...] déspota», que cambia en 1984 por «forma rumana o ucrania del ruso gospodar', señor». El DUE indica igualmente su incorporación del rumano, señalando la posibilidad de su entrada también mediante el ucraniano («forma rumana o ucraniana del ruso gospodar', señor»). 
icono (también ícono, Am.). Aunque se incorpora al DRAE-1956 como un préstamo del griego («Del gr. દíஸ́v»), el elemento icono es considerado como galicismo desde el DRAE-2001, cuando registra también la forma icono (DLE-2014: «Del fr. icône, este del ruso ikona, y este del gr. bizant. દíkóv, -óvos eikốn, -ónos»). En el $D E C H$ de Coromines y Pascual se indica también la entrada del término mediante el francés: "Alguna vez, en traducciones del ruso por conducto del francés, se ha empleado un sustantivo icono 'imagen del culto ortodoxo', mala adaptación de este vocablo griego: debería decirse icon, plural ícones» (Coromines y Pascual 2012 [19801991], s. v. icono). Buchi en su descripción sigue a Coromines y Pascual.

menchevique. Es un préstamo del ruso incorporado vía francés, según el $D R A E-1992$ (DLE-2014: «Del fr. menchevik, y este del ruso men'shevik; literalmente 'uno de la minoría', infl. en su forma por bolchevique»). Buchi también indica la entrada del término vía francés y menciona el uso de este adjetivo con función del sustantivo (formas menchevik y menshevik) en las primeras etapas de su incorporación al español, estableciendo una clara analogía entre dicho término y el antes descrito bolchevique.

\subsubsection{Divergencia de los datos etimológicos en las fuentes lexicográficas}

En segundo lugar, describiré los préstamos de origen ruso que ofrecen indicaciones de procedencia diversas en los diccionarios revisados. Aportaré los datos etimológicos de los diccionarios que difieren en su descripción de las informaciones de la vigésima tercera edición del Diccionario de la lengua española, añadiendo, cuando sea posible, los detalles acerca de la procedencia comentados por los autores.

Como se ha mencionado antes, las diferencias en las consideraciones etimológicas sugieren la necesidad de una investigación más detallada de las vías de incorporación al español de los siguientes términos de origen ruso:

astracán. El préstamo se registra en el $D R A E-1914$ con la indicación «por haberse fabricado por primera vez en la ciudad rusa de este nombre». Desde el 1936 hasta el 1956 carece de marca etimológica alguna y desde el 1970 se presenta como un rusismo (DLE-2014: «De Astracán, ciudad rusa del Caspio»). El DUE apoya la teoría del rusismo («de Astrajan, nombre de la ciudad rusa donde empezó a prepararse esta piel), mientras que el DECH de Coromines y Pascual y los diccionarios Vox y Larousse señalan la incorporación del préstamo vía francés (Coromines y Pascual: «del fr. astracan íd. y éste [sic] de Astrakhan, grafía francesa del nombre de la ciudad rusa de Astraján, a orillas del Caspio, de donde se importó este tejido»; Vox: «Préstamo del francés astracan y éste [sic] de Astrakhan, grafía francesa de Astraján, ciudad rusa de donde se importaba la piel»; Larousse: «Del fr. lt Astraján, ciudad rusa»).

balalaica. Desde su incorporación al DRAE, en 1956, el préstamo ha recibido la consideración de rusismo (DLE-2014: «Del ruso balalaika»). Sin embargo, los datos del $N D H E$ indican que la incorporación de dicho término se ha realizado vía francés: «Etim. Voz tomada del francés balalaika, procedente a su vez del ruso balalaïk; aunque se suele apuntar a un origen directo del ruso, el hecho de que el primer testimonio del vocablo se localice en el folletín "El banquete chino", en 1816, aclara las vías del préstamo, pues nos hallamos ante una traducción de la pieza francesa "Le repas chinois, traduit d'un voyage inedit", publicada en Bibliothèque britanni- 
que, ou Recueil extrait des Ouvrages Anglais périodiques et autres, vol. 52, 1813...» (NDHE, s. v. balalaika, consulta 25.05.2016)

El NDHE señala, además, que la forma balaleiga —una variante del término- ha sido igualmente incorporada al español vía francés, en el que dicho elemento, a su vez, presentaba una «variante de balalaïka (1768), procedente del ruso balalaïka 'instrumento musical de cuerda de caja triangular'» (NDHE, s. v. balalaika, consulta 25.05.2016). Buchi también sugiere la entrada de balalaica a través del francés, indicando que su hipótesis se basa en el propio tipo del préstamo, que, según la autora, podría ser incorporado al español como resultado de las traducciones de las novelas rusas sobre la base de su traducción al francés. El uso en español de la forma balaleiga, típica del francés del siglo XIX, también fortalece dicha teoría, en palabras de Buchi.

beluga. El término aparece por primera vez en el $D L E-2014$, siendo una de las novedades de la edición respecto a la inclusión de los préstamos de origen ruso. La marca etimológica del préstamo lo define como rusismo («Del ruso beluga, de belo'blanco' y -uga, suf. aum.»). El DUE indica igualmente que se trata de una palabra incorporada del ruso («de or. ruso»). Buchi, sin embargo, asigna la incorporación del término a la lengua francesa, explicando su hipótesis por un cambio de género poco habitual en español.

isba. Desde el $D R A E-1984$, se indica la incorporación de esta palabra rusa vía el propio ruso (DLE-2014: «Del ruso izbá»), aunque el préstamo no presentaba ninguna marca etimológica desde su primer registro en el DRAE-1936. El DUE y el Diccionario Larousse también señalan que el término es un rusismo (DUE: «del ruso izbá, casa rural»; Larousse: «De ruso»). No obstante, el Diccionario crítico etimológico castellano e hispánico indica que el término es «tomado del ruso izbá 'casa rural, provista de calefacción, por conducto del fr. isba de las traducciones de novelas rusas» (Coromines y Pascual 2012 [1980-1991], s. v. isba). Es, por lo tanto, un galicismo. Buchi también sugiere la entrada del término a través del francés, explicándolo por el uso de la grafía $<\mathrm{s}>$, no justificado para el español que dispone de la grafía $<\mathrm{z}>$.

kopek (también copec). Desde su entrada en el DRAE en 1992, dicho préstamo ha sufrido varias modificaciones en su grafía; la indicación etimológica que le acompaña, sin embargo, no ha cambiado. El préstamo es un rusismo, según el DRAE («Del ruso kopeika»). Buchi, a su vez, sugiere que se trata de un préstamo del francés, explicando su teoría por la correspondencia de formas en español y en francés en los niveles fonético y gramatical. La autora afirma que el étimo directo que determinó la entrada del término en el francés podría ser la forma del genitivo, kopéek, cuya pronunciación rápida /-pek/ parece reflejarse en la grafía de las formas francesas en $-k$. De allí procederían las formas en $-k$ registradas en español.

kremlin. Desde su entrada en el DRAE-1992, el término se ha considerado como rusismo («Del ruso kreml 'ciudadela'»). El Diccionario Vox presenta datos semejantes: «Préstamo del ruso, derivado de kreml' 'fortaleza'». Eva Buchi, no obstante, afirma que el término en acepción de 'fortaleza' podría ser difundido en las lenguas iberorrománicas vía el francés, que, a su vez, había adquirido el préstamo del alemán; con su significado 'Gobierno de la URSS' el elemento podría ser transmitido 
en las lenguas occidentales mediante el inglés. Aunque se trata de una teoría carente de fundamentos documentados, parece oportuno mencionarla.

politburó. El registro del préstamo es una novedad en la vigésima tercera edición del Diccionario de la lengua española. De acuerdo con los datos presentados, el término es un rusismo («Del ruso politbiuró, contracc. de politícheskoye biuró 'oficina política'»). El DUE presenta los mismos datos («de or. ruso»). Buchi considera que la incorporación del término podría haberse realizado mediante el francés, dada la aparición de la grafía <-eau-> en las primeros casos del empleo de la palabra.

pope. El préstamo se recoge por primera vez en el DRAE-1936 sin indicación etimológica, que aparece en la edición de 1992 destacando que el término es un rusismo («Del ruso pop 'sacerdote'»). El DECH también señala, dentro de la entrada de $p a-$ $p a$, que el término se ha incorporado vía el ruso: «El ruso pop 'sacerdote', del mismo origen, se ha castellanizado en la forma pope» (Coromines y Pascual 2012 [1980-1991], s. v. papa). El Diccionario Larousse es de la misma consideración («Del ruso, sacerdote»). Buchi, no obstante, opina que el préstamo podría haber sido incorporado vía el francés, dada la semejanza entre las formas y el uso de la palabra con el término utilizado por autores franceses en los relatos de viajes por Rusia. Igual que en el caso anterior, la teoría carece de documentación.

ucase. Desde su incorporación al DRAE en 1899, el término ha sido tratado como rusismo, aunque ha habido modificación en la forma que dio origen al préstamo (DRAE1899: «Del ruso ukazati, indicar»; DRAE-1992: «Del ruso ukaz, decreto»). Varias fuentes, no obstante, han afirmado que el término entró en español mediante el francés. Tales son los casos del $D E C H$ de Coromines y Pascual («tomado, por conducto del fr. ukase, del ruso ukáz 'edicto imperial', derivado de ukazat 'indicar'»), Larousse («Del fr., ruso, edicto imperial») y Buchi (afirma — aunque sin documentación necesariaque la retransmisión a las lenguas iberorrománicas se realizó en el siglo XIX mediante el francés que había incorporado el término en el siglo XVIII).

zar. El préstamo apareció en las páginas del $D R A E$ en el 1780 sin ningún tipo de indicación etimológica. En la edición de 1884 se ha registrado por primera vez como rusismo («Del ruso tsar»), y en el $D L E-2014$ se han aportado algunos detalles sobre la forma femenina («Del ruso tsar; la forma f., del al. Zarin»). El Diccionario Larousse incluye la misma indicación de la incorporación de la palabra («Del ruso»). De acuerdo con Buchi, la entrada vía el ruso debería estar excluida por la aparición del dígrafo $<\mathrm{cz}>$ en las primeras formas del préstamo, por lo que la autora propone considerarlo un galicismo.

zarévich. En el $D R A E$, el préstamo es tratado como rusismo desde su registro en 1992 (DLE-2014: «Del ruso tsarevich»). El Diccionario Larousse no difiere del $D R A E$ ( «Del ruso»). Igual que en el caso de zar, Buchi sugiere la incorporación del término mediante el francés a causa de sus primeros registros con el dígrafo $<\mathrm{cz}>$.

\subsection{Novedades del registro de los préstamos del ruso en el DLE-2014}

Puesto que en mi comparación parto de los datos de la vigésima tercera edición del Diccionario de la lengua española, considero oportuno indicar las novedades anotadas respecto al registro de los préstamos de origen ruso. El DLE-2014 indica la incorpora- 
ción directa del ruso de dos términos registrados sin ninguna marca etimológica en las ediciones anteriores, introduce cinco términos — carentes de registro anterior- de origen ruso y señala la procedencia del ruso de un término incorporado vía otro idioma. A continuación, haré una breve descripción de dichos términos comparando de nuevo los datos etimológicos del $D L E-2014$ con la información de otros diccionarios.

La primera modificación respecto a los préstamos de origen ruso que presenta el DLE-2014 está relacionada con la integración de la marca etimológica que señala la incorporación directa del ruso en las entradas de dos términos registrados en las ediciones anteriores. Se trata de los siguientes préstamos:

versta. Registrado por primera vez en el $D R A E-1936$, el término va acompañado en el $D L E-2014$ de la indicación «Del ruso versta», lo que le otorga la consideración de un rusismo. Buchi también sugiere que se trata de un préstamo directo del ruso, mientras que los demás diccionarios -el término se halla registrado casi en todas las fuentes - no incluyen ningún tipo de marca etimológica.

vodka (también vodca). El primer registro del término en el DRAE-1936 (y con la forma vodca en la edición de 1970) no revela datos sobre su etimología, mientras que el DLE-2014 lo presenta como un rusismo ( $(\mathrm{Del}$ ruso vodka, dim. de voda 'agua'»). Todas las fuentes seleccionadas incluyen dicho término, pero ninguna, excepto Buchi (quien sugiere la incorporación del ruso) añade datos etimológicos.

Además de modificar las entradas ya existentes, el DLE-2014 introduce cinco nuevos términos de origen ruso. Son los siguientes vocablos:

beluga. Como se ha descrito en las páginas anteriores, el término, que designa «Esturión de gran tamaño que habita en los mares Negro y Caspio», «Caviar muy apreciado que se obtiene del esturión beluga» $\mathrm{y}$ «Cetáceo de piel blanca que vive en los mares árticos» (DLE-2014, s. v. beluga), se incluye en el DLE-2014 con la marca etimológica que lo define como rusismo («Del ruso beluga, de belo- 'blanco' y -uga, suf. aum.»). El DUE presenta datos semejantes («de or. ruso»), mientras que Buchi argumenta a favor de la incorporación del término a través del francés. Aparte de los diccionarios mencionados, el término está registrado en el Diccionario Vox, el Diccionario Larousse y el $D E A$, sin marca etimológica.

blinis. El término se incluye en el $D L E-2014$ con el significado «Torta fina de harina y otros ingredientes» (DLE-2014, s. v. blinis) y con la nota «Del ruso bliny, pl. de blin». Como se ha comentado antes, Éva Buchi sugiere en su estudio que se trata de un galicismo, sin presentar, sin embargo, datos suficientes que apoyen dicha teoría. El Diccionario esencial de la lengua española, el DEA y el DUE incluyen el préstamo sin indicar su procedencia.

inteligencia. Con las acepciones «Conjunto de intelectuales de un país» y «Conjunto de ideas y valores de una comunidad, de un país, etc.» (DLE-2014, s. v. inteligencia), el préstamo está recogido en el DLE-2014 con la indicación «Del ruso intelligentzia». Aparte del DRAE, tan solo los diccionarios de Buchi y Moliner incluyen el término, marcándolo como rusismo. 
nomenklatura (también nomenclatura). Cuando significa «Conjunto de altos cargos políticos de la antigua Unión Soviética o de sus países aliados y, por ext., de otros sistemas políticos») (DLE-2014, s. v. nomenklatura), el término es un rusismo, de acuerdo con el DLE-2014 («Del ruso nomenklatura, y este del lat. nomenclatūra 'lista de nombres'»). Dicha acepción del término tan solo se menciona en los diccionarios de Buchi y Moliner, que indican que se trata de un rusismo.

politburó. Como se ha visto antes, el préstamo, que denomina «En la antigua Unión Soviética y en otros países comunistas, comité en el que reside la autoridad política del país», va acompañado de la indicación «Del ruso politbiuró, contracc. de politícheskoye biuró 'oficina política'» en el DLE-2014. El DUE también lo trata como un rusismo («de or. ruso»). Éva Buchi considera probable la incorporación del término vía el francés. El DEA y el Diccionario Vox no indican la procedencia.

Por último, el siguiente término ha visto modificada su marca etimológica con la inclusión del ruso como lengua de origen:

estepa. El $D L E-2014$ señala el origen ruso y la incorporación vía el francés de este préstamo, que apareció sin marca etimológica en el $D R A E-1884$, fue marcado como rusismo en la edición de 1899 e indicado como galicismo en 1922. Tanto el DECH como Buchi señalan la incorporación mediante el francés de este término con origen ruso.

Todo lo descrito confirma que, entre los préstamos de origen ruso registrados en las páginas de la vigésima tercera edición del Diccionario de la lengua española, se hallan tanto los rusismos, que han entrado en español vía el propio ruso, como los términos que, a pesar de su procedencia rusa, se han incorporado al vocabulario del español como consecuencia de un contacto directo con otro idioma. La vigésima tercera edición del $D R A E$ incluye en sus páginas no menos de treinta y ocho términos de origen ruso, treinta y dos de los cuales han recibido, de acuerdo con sus marcas etimológicas, la consideración de rusismos, y los seis restantes deben su origen al idioma ruso o fueron transmitidos al español vía el ruso como una lengua intermediaria.

La comparación de los datos etimológicos del $D R A E$ con la información acerca de la procedencia e incorporación de estos términos en una serie anteriormente descrita de fuentes lexicográficas revela que, por un lado, la mayoría — veintiuno, para ser exactos- de los rusismos del DLE-2014 están definidos como tales en los demás diccionarios (lo que lleva a la conclusión de que la mayoría de los términos de origen ruso presentes en el vocabulario del español se incorporaron al idioma debido al contacto directo con el propio ruso), y seis términos de origen ruso, de acuerdo con el DRAE y algunas de las fuentes seleccionadas, deben su incorporación al español a otro idioma. Por otro lado, once préstamos, recogidos como rusismos en el $D R A E$, presentan distintos datos acerca de su incorporación en al menos uno de los diccionarios revisados.

Cabe anotar el papel del francés en la incorporación de los términos de origen ruso al español. De seis términos cuya incorporación al español no se realizó directamente del ruso, cinco están marcados, tanto por el $D R A E$ como por alguno de los demás diccionarios, como galicismos (uno de ellos también podría haber sido incorporado vía el italiano). Y cada uno de los once términos de origen ruso cuyas indicaciones de incor- 
poración en los diccionarios revisados difieren de los datos del DLE-2014 está recogido en al menos una de las fuentes seleccionadas como galicismo (aunque en algunos casos se trata de hipótesis no confirmadas). Las disimilitudes en las indicaciones etimológicas del $D L E-2014$ y del resto de las fuentes lexicográficas consultadas justifican la necesidad de profundizar en la historia de la incorporación de los términos de origen ruso a la lengua española, con el objetivo de reafirmar los datos presentados o modificarlos.

\subsection{Necesidad de incorporar un número más elevado de términos de origen ruso al DRAE}

Otro asunto respecto al registro de los préstamos de origen ruso en las fuentes lexicográficas del español que requiere investigación más detallada es la necesidad de la incorporación de un número mayor de términos. Los registros de los rusismos y préstamos de origen ruso en la serie de fuentes lexicográficas seleccionadas, su uso en el habla y los escritos de la actualidad, igual que su empleo en los corpus de la RAE revelan un número de préstamos considerablemente mayor a los treinta y ocho elementos incluidos en el $D L E-2014$. La decisión acerca del registro de un nuevo préstamo en el $D R A E$ es, no obstante, compleja y requiere un estudio previo de una multitud de criterios. Se describirá, a continuación, un análisis de una serie de préstamos de origen ruso no registrados en el $D R A E$, que, sin pretender ser exhaustivo, presenta un intento de responder a la pregunta de si es argumentada o no su inclusión en el Diccionario.

La investigación se desarrolló en dos fases: en la primera, se elaboró una lista de los préstamos que debían ser analizados; en la segunda, se procedió con el análisis de su uso e integración en el idioma español. Con el objetivo de elaborar una lista de los posibles préstamos de origen ruso, fueron consultadas dos fuentes: por una parte, el Banco de neologismos del Centro Virtual Cervantes, que presenta los neologismos detectados en un corpus de medios de comunicación de 2004 a 2010 y que dio como resultado diecinueve términos distintos del ruso; por otra parte, Bolchevik, mazout, toundra et les autres: dictionnaire des emprunts au russe dans les langues roman de Éva Buchi que ofrece una recopilación de los rusismos y préstamos de origen ruso registrados en alguno de los documentos en español con los que trabajaba la autora, con el número total de ciento quince préstamos.

Después de elaborar la lista, se procedió con la búsqueda de los términos recogidos en las fuentes lexicográficas seleccionadas para la primera etapa de la investigación. El registro de los términos en al menos un diccionario de los consultados se consideró necesario para seguir con el estudio de su uso, puesto que, para la inclusión de un término en el $D R A E$, debe ser verificado su uso en el español actual, y las fuentes seleccionadas - diccionarios de calidad y prestigio - incluyen los elementos con la vigencia actual comprobada.

El estudio continuó con la consulta de los términos seleccionados en los corpus CORDE, CREA y CORPES XXI de la RAE y la Hemeroteca Digital de la Biblioteca Nacional de España. Dichos recursos permitieron recopilar los datos tanto acerca de la frecuencia del uso de los términos consultados en distintas épocas, como sobre los contextos temáticos y los registros textuales en los que los hablantes del español recurren a dichos elementos. Se consideró importante que un término de origen ruso cuya inclusión en el DRAE pudiera ser sugerida presentara un uso relativamente estable, 
tanto en los corpus como en la Hemeroteca Digital, puesto que el Diccionario de la lengua español refleja en sus páginas el léxico con el uso consolidado en español. Los significados con los que aparecían dichos términos fueron igualmente observados con el fin de detectar si dichos préstamos han desarrollado acepciones nuevas, distintas de las que presentan en ruso. Por último, fueron analizadas las formas gráficas de los términos para valorar el grado de su integración en la lengua española.

Como resultado de dicho planteamiento teórico, la primera lista de los términos, que incluía los elementos indicados por el Banco de neologismos del Centro Virtual Cervantes y por el estudio de Éva Buchi, constaba de más de ciento veinte palabras. Dicha lista incluía los términos como kabak, osmina, polusca, agit-prop y kasha. Se excluyeron de la búsqueda posterior los términos registrados en el $D L E-2014$, la mayoría de los cuales figuraba en la lista. La búsqueda de los elementos restantes en los diccionarios redujo la lista hasta poco más de veinte términos, tales como matrioska, sovjós, apparatchik, knut y kvas (también kwas). Dicha reducción considerable del número de términos podría deberse a que algunas palabras, recogidas por los autores en su uso esporádico y ocasional, no hayan consolidado su empleo en la lengua y, por tanto, no hayan sido registradas en los diccionarios; igualmente podría tener como causa el uso limitado a los escritos del ámbito muy específico. Es oportuno mencionar, asimismo, que cierto número de los términos marcados por el diccionario de Buchi como rusismos o préstamos de origen ruso en español se halla con indicaciones de procedencia distintas en las obras consultadas, por lo que no se prosiguió con su consulta en los corpus ni en la Hemeroteca Digital. Por último, la consulta de los términos de la lista reducida en los corpus y la Hemeroteca Digital permitió realizar la selección final.

De acuerdo con los datos del análisis descrito, cuatro préstamos de origen ruso presentan características requeridas para que sea considerada la posibilidad de su inclusión en el DRAE. El resto de los términos se usa escasamente en los textos de los corpus y la Hemeroteca Digital, debido, al parecer, a la falta de conocimiento acerca de los conceptos que designan de parte de la población hispanohablante o al empleo en un ámbito muy específico. Son, por ejemplo, los casos de borsch y koljós.

Así, a pesar de estar registrado como rusismo en el $D E A$ y los diccionarios de María Moliner y Éva Buchi, el término borsch presenta un uso exiguo tanto en los corpus como en la Hemeroteca Digital. Se emplea, generalmente, en recetas o novelas relacionadas con Rusia. Además, su grafía es todavía inestable: los corpus registran variantes borsch y borscht, mientras Buchi da ejemplos de bortscht, borsh y borsht, entre otros. Se trata, por lo tanto, del préstamo en su primera fase de la incorporación al idioma, denominada «el momento de la transferencia» en la clasificación de Juan Gómez Capuz (2005: 15). Es probable que el mayor conocimiento de los hispanohablantes sobre el tipo de la sopa que describe el término - siendo este el resultado de un contacto más frecuente con la cultura rusa - condicione su inclusión en el DRAE más tarde.

A su vez, el elemento koljós, incluido en el $D E A$, las obras de Moliner y Buchi y los diccionarios de Vox y Larousse, aunque parece estabilizar su uso en el CREA en comparación con el CORDE — aun así, se trata de un número de usos más bien escaso-, 
presenta registros exiguos en CORPES XXI. Puesto que designa «Cooperativa agrícola soviética en que las tierras son cedidas por el Estado y explotadas por la comunidad» (DUE 2007, s. v. koljós), se emplea mayoritariamente en los textos de carácter histórico-politico relacionados con la URSS. La forma gráfica varía mucho: Buchi registra las variantes como koljos, koljoz, coljós y koljocz. De ahí que el término parezca un exotismo en la primera etapa de su incorporación al español —el momento de la transferencia, según Gómez Capuz - y, dado que designa un concepto inexistente en la actualidad, resulte poco probable que se consolide en el idioma, siempre que el concepto no sea revivido.

En cuanto a los cuatro términos cuya incorporación al DRAE podría ser considerada, describiré cada uno de ellos presentando argumentos a favor de su inclusión:

kalashnikov. El DUE indica que se trata de una «marca registrada, de Mijaíl Kalashnikov, inventor de este fusil...», mientras que Buchi considera la posibilidad de la incorporación de este préstamo de origen ruso vía el inglés, debido a la grafía $<$ sh $>$. Los datos de los corpus y la Hemeroteca Digital señalan el uso creciente del término que aparece en los textos en español desde los años setenta del siglo XX (en el CREA se registra desde los años noventa). Se anota que el préstamo presenta variantes de escritura con y sin tilde, con mayúscula y minúscula inicial, lo que podría explicarse por pocos registros que presenta en los diccionarios. No se observa cambio de significado. El término es un nombre propio convertido en un nombre común, que designa «Fusil de asalto de fabricación soviética» (DUE 2007, s. v. kalashni$k o v)$. El uso creciente del término y la importancia que no pierde en el mercado el objeto que designa aseguran, según considero, su empleo en español en el futuro y, por lo tanto, la necesidad de la incorporación del término al DRAE.

glasnost. El término, que denota «Política de transparencia promovida por el presidente soviético Mijaíl Gorbachov a finales de los años ochenta del siglo XX» (DUE 2007 , s. v. glasnost), se recoge como rusismo en el DUE, en el diccionario de Buchi, en el DEA y en el Diccionario Larousse. El préstamo se emplea en los textos de política, economía, comercio, finanzas y ciencias sociales que hacen referencia a Rusia o la URSS, mayoritariamente junto al otro término — perestroika - registrado como rusismo en el DRAE. La palabra no modifica la grafía ni tampoco crea nuevas acepciones. La frecuencia de su uso, considerable en los corpus (desde el CREA) y la Hemeroteca Digital debido a la importancia del concepto descrito en la historia del pueblo ruso, y el hecho de la inclusión del término perestroika en el DRAE sugieren la posibilidad del registro de este término en las páginas del Diccionario.

mujik. Este término designa «En la Rusia de la época de los zares, campesino» (DUE 2007, s. v. mujik) y aparece como rusismo en el DUE, no va acompañado de indicación etimológica en el $D E A$ ni el Diccionario Larousse y se considera como un posible galicismo por Buchi, quien justifica su hipótesis por la grafía $<\mathrm{j}>$, presente en muchas formas posibles del término recogidas por la autora (mujich, mujick, moujik, mujic y muzhik). Aunque el empleo del término en los corpus no puede denominarse frecuente, se caracteriza por ser estable e incluso creciente en el CORPES $\mathrm{XXI}$, que, como los demás corpus, refleja el uso mayoritario del préstamo en las novelas, relatos, obras de teatro y textos sobre política, economía y justicia relaciona- 
dos con Rusia. El término no cambia de significado pero presenta un grado muy alto de variación gráfica. La posibilidad de la inclusión de dicho termino en el DRAE debería considerarse, también, dado a la enorme frecuencia de su uso en la Hemeroteca Digital, lo que refleja el hecho de que, en palabras de Buchi, se trata de la designación de un representante emblemático de la sociedad zarista rusa.

sputnik. Dicho término, que presenta «Nombre de los primeros satélites artificiales que lanzaron los soviéticos» (Moliner 2007, s. v. spútnik), aparece como rusismo en las páginas de los diccionarios de Moliner y Buchi, en el DEA y en el Diccionario de Larousse. El uso del término aumenta tanto en la Hemeroteca Digital como los corpus, en los que se registra en su mayoría en los textos relacionados con la ciencia, tecnología, ciencias sociales, política y economía. La grafía del préstamo, aparte de las variantes con o sin tilde, resulta estable. Se aconseja considerar la posible inclusión de dicho rusismo en el $D R A E$ puesto que su empleo se debe al significado más preciso que el del término español satélite, y, además, se han encontrado usos metafóricos del término — que reflejan un alto grado de incorporación al idioma-, como es el caso de «sentí que me iba alejando poco a poco, como un sputnik viviente al que aguardaba la muerte cuando se agotase el oxígeno» («La vida de un astronauta en la MIR», La Prensa de Nicaragua. Informática, 20/03/01, vía CORPES XXI).

El estudio de la necesidad de incorporar un número mayor de rusismos o términos de origen ruso al español ha revelado que, en contra de mis expectativas, de más de ciento veinte términos recogidos de las fuentes seleccionadas, solamente cuatro parecen poseer características necesarias para que pudiera ser considerada su incorporación al $D R A E$. El resto de los términos que se registran en los diccionarios, los corpus y la Hemeroteca Digital no presentan una frecuencia del uso requerida para justificar su inclusión en el $D R A E$, dato que puede cambiarse en el futuro como consecuencia del aumento de la conciencia de la población hispanohablante sobre la cultura rusa. A diferencia de dichos términos, el nivel de conocimiento acerca de las realidades designadas por los rusismos kalashnikov, glasnost, mujik y sputnik, reflejado en la frecuencia del empleo de estos préstamos, sugiere la necesidad de reflexionar acerca de la posibilidad de su incorporación al $D R A E$.

\section{CONCLUSIÓN}

Los contactos históricos entre España y Rusia, aunque carentes de estabilidad hasta el último cuarto del siglo XX, han ido dejando constancia del saber acerca de la cultura e historia del otro pueblo en el idioma. De acuerdo con los resultados de esta investigación, la vigésima tercera edición del $D R A E$ recoge en sus páginas no menos de treinta y ocho términos de origen ruso. Aunque denominan las costumbres, realidades culturales y eventos históricos del pueblo ruso, algunos de estos préstamos se han incorporado al vocabulario del español como resultado de un contacto directo con otro idioma.

La comparación de los datos etimológicos del $D R A E$ con las indicaciones de la procedencia e incorporación de estos préstamos en una serie previamente seleccionada de fuentes lexicográficas ha revelado que, de acuerdo con los datos de los diccionarios consultados, la mayoría - veintiuno - de estos elementos entraron en español directamente del ruso, por lo que se definen como rusismos (son los casos de dacha, duma, 
samovar, vodka); seis de dichos préstamos provienen del ruso o fueron transmitidos al español a través del ruso como una lengua intermediaria pero su incorporación al español se debe al contacto directo con otra fuente lingüística (bolchevique, cebellina, hospodar), y once préstamos, rusismos según el $D L E-2014$, ofrecen datos que indican su entrada vía otro idioma, en su mayoría el francés, en alguno de los diccionarios revisados (balalaica, isba, zar). De los treinta y ocho términos de origen ruso recogidos en el $D L E-2014$, cinco son elementos nuevos, carentes del registro previo en el DRAE (beluga, blinis, inteligencia, nomenklatura, politburó), dos han recibido consideración de rusismos a pesar de no ir acompañados de ninguna marca etimológica en las ediciones anteriores (versta y vodka - también vodca-) y un término ha recuperado la indicación de su procedencia - aunque no de la incorporación - del ruso (estepa).

Las disimilitudes en las marcas etimológicas del DLE-2014 y alguna de las fuentes lexicográficas consultadas sugieren la necesidad de una investigación más detallada acerca de la historia de la incorporación de algunos términos de origen ruso en español, con el objetivo de reafirmar o modificar los datos indicados en la vigésima tercera edición del DRAE. Por otro lado, el análisis de los préstamos de origen ruso registrados en el $D L E$-2014 señala la necesidad de considerar la posibilidad de incorporar un número más elevado de los préstamos del ruso al Diccionario. La investigación de dicha necesidad ha revelado que, de más de ciento veinte términos considerados en el estudio, cuatro (kalashnikov, glasnost, mujik y sputnik) parecen poseer las características necesarias - entre las cuales destaca el uso estable en los corpus, que, a su vez, refleja el conocimiento de las realidades designadas - para que pudiera ser considerada su incorporación en el DRAE.

\section{REFERENCIAS BIBLIOGRÁFICAS}

Biblioteca Nacional de España. Hemeroteca Digital. En línea: http://www.bne.es/es/Ca talogos/HemerotecaDigital/. [Fecha de consulta: 15/10/2015]

BucHI, Éva (2010): Bolchevik, mazout, toundra et les autres: dictionnaire des emprunts russes dans les langues romanes: inventaire, histoire, intégration, Paris, CNRS Éditions.

CÁMARA, Manuel de la (2010): «Las relaciones entre España y la Federación Rusa», Anuario internacional CIDOB, 1, pp. 449-459.

CORDE. Real ACAdemia EsPañola. Corpus Diacrónico del Español. En línea: http://www.rae.es. [Fecha de consulta: 15/10/2015]

CORPES XXI. Real ACADEmia EspaÑola. Corpus del Español del Siglo XXI. En línea: http://www.rae.es. [Fecha de consulta: 15/10/2015]

CREA. Real ACADEMia Española. Corpus de Referencia del Español Actual. En línea: http://www.rae.es. [Fecha de consulta: 15/10/2015]

DEA. Manuel SECO, Olimpia de ANDRÉS y Gabino RAMOs $\left(2011^{2}\right)$ : Diccionario del español actual, Madrid, Aguilar.

DECH. Joan CoRomines y José Antonio Pascual (2012 [1980-1991]), Diccionario crítico etimológico castellano e hispánico, CD-ROM, Madrid, Gredos. 
Diccionario Larousse. Sofía ACEBO GARCíA, ed. $\left(2012^{4}\right)$ : Larousse: Gran Diccionario de la Lengua Española, Barcelona, Larousse.

Diccionario Vox. David AGUILAR et al., redact. $\left(2009^{2}\right)$ : Diccionario general de la lengua española Vox, Barcelona, Larousse.

DLE-2014. ReAl ACADEMIA ESPAÑola $\left(2014^{23}\right)$ : Diccionario de la lengua española. En línea: http://www.rae.es.

DUE. María MOLINER $\left(2007^{3}\right)$ : Diccionario de uso del español, Madrid, Gredos.

GARRIDO CABALLERO, Magdalena (2008): Las relaciones entre España y la Unión Soviética a través de las Asociaciones de Amistad en el siglo XX, tesis doctoral. En línea: https://digitum.um.es/xmlui/handle/10201/186. [Fecha de consulta: 15/10/2015]

GÓMEZ CAPUZ, Juan (1998): El préstamo lingüístico: conceptos, problemas y métodos, Valencia, Universitat de València.

Gómez CAPUZ, Juan (2005): La inmigración léxica, Madrid, Arco/Libros.

InSTITUTO CERVANTES. Banco de neologismos. En línea: http://cvc.cervantes.es/lengua/banco neologismos/. [Fecha de consulta: 15/10/2015]

NDHE. REAl ACADEMIa ESPaÑola. Nuevo diccionario histórico del español. En línea: http://www.rae.es. [Fecha de consulta: 25/05/2016]

PRATT, Chris (1980): El anglicismo en el español peninsular contemporáneo, Madrid, Gredos.

Real ACAdemia Española (2005): Diccionario del estudiante, Madrid, Real Academia Española.

ReAl ACADEMia Española (2006): Diccionario esencial de la lengua española. En línea: http://www.rae.es.

REAL ACADEMIA ESPAÑola. Nuevo Tesoro Lexicográfico de la Lengua Española. En línea: http://www.rae.es.

YÁKOVLEV, Petr (2001): «Rusia y España: de la asociación estratégica al partenariado para la modernización», Iberoamérica, 2, pp. 47-67.

\section{TÍTULO/TITLE}

«Incorporación directa e indirecta de los préstamos de origen ruso al español y nuevos términos» «Direct and indirect incorporation of borrowings from Russian into Spanish and new loanwords»

Fecha de presentación: 29/05/2017 Fecha de aceptación: 29/01/2018

Resumen: El objetivo de esta investigación consiste en determinar las vías de incorporación de los préstamos de origen ruso al español y en definir la necesidad de incorporar un número más elevado de dichos elementos en las fuentes lexicográficas del español. Se pretende señalar la vía - directa o indirecta- de la entrada de los términos del ruso en español mediante la comparación de los datos etimológicos en una selección de fuentes lexicográficas del idioma. De la misma manera, mediante el análisis de uso de una serie de elementos rusos que presentan un registro esporádico en los diccionarios y bases de datos de neologismos utilizados, se pretende destacar los que reúnan características necesarias para que pudiera ser considerada su incorporación en el $D L E$.

Palabras clave: préstamo; rusismo; incorporación; léxico. 
Abstract: This study aims to determine the ways of borrowing from Russian into Spanish and to identify the need to incorporate a larger number of these loanwords into the Spanish lexicographic sources. This research aims to determine direct and indirect borrowing from Russian language into Spanish by comparing the etymological data in a series of Spanish lexicographic sources. By analysing the uses of a series of loanwords from Russian which have been sporadically registered in dictionaries and neologism databases, this paper aims to identify the loanwords whose characteristics allow them to be considered for incorporation into the Spanish Language Dictionary.

Key words: borrowing; loanword; loanword from Russian; vocabulary. 